\title{
Where do clonal coral larvae go? Adult genotypic diversity conflicts with reproductive effort in the brooding coral Pocillopora damicornis
}

\author{
David J. Ayre*, Karen J. Miller \\ Institute for Conservation Biology and Department of Biological Sciences, University of Wollongong, Wollongong, \\ New South Wales 2522, Australia
}

\begin{abstract}
Earlier studies of the coral Pocillopora damicornis provide a conflicting picture of its use of sexual and asexual reproduction for population maintenance. In Western Australia, colonies are asexually viviparous, and populations appear to be maintained by localised asexual recruitment but founded by genotypically diverse colonists. However, on Australia's Great Barrier Reef (GBR), as in many other regions, populations display little or no evidence of any asexual recruitment. We used allozyme electrophoresis to test for asexual input into local populations of $P$. damicornis at One Tree Island on the southern GBR. Contrary to expectation we found that all of 136 planulae and 90 metamorphosed settlers from 11 reef flat and reef-crest colonies were electrophoretically identical to their broodparents. Moreover, for each colony, between 5 and 30 juveniles or settlers and their broodparent were identically heterozygous at 1 or more loci. We conclude that for the southern GBR the primary mode of reproduction involves the asexual generation of brooded larvae. However, samples of 30 adult $(>15 \mathrm{~cm})$ and 29 to 30 juvenile $(<7 \mathrm{~cm})$ colonies, from each of 4 sites, showed little evidence of asexually derived recruitment. On average, 7 -locus genotypic diversity $\left(G_{0}: G_{e i}\right.$ observed:expected) within samples was 90 and $81 \%$ respectively of the diversity expected for random mating, and $62 \%$ of the 238 colonies sampled displayed electrophoretically distinct phenotypes. Our data therefore challenge the established paradigm that predicts that organisms with complex life-cycles use asexual reproduction to maintain locally adapted clones and sexual reproduction to produce widely dispersed colonists.
\end{abstract}

KEY WORDS: Genetics $\cdot$ Planulae $\cdot$ Asexual $\cdot$ Clonal $\cdot$ Reproduction $\cdot$ Spatial heterogeneity

\section{INTRODUCTION}

The last 3 decades have yielded both an increasingly sophisticated understanding of the molecular biology of reproduction (recombination and DNA replication), and a variety of models that seek to explain the shortto-medium-term roles of sexual reproduction. However we have seen little conceptual advance in our understanding of the contrasting roles that sexual and asexual reproduction play within complex life-cycles. The value of sexual reproduction has variously been argued to lie in generating genetic novelty utilised in 'parasitic arms races' and immune responsiveness (Seger \& Hamilton 1988, Lively 1992, Galvani et al. 2003) and as an element of the DNA repair mechanism (Bernstein et al. 1988), or as a means of overcoming the accumulation of deleterious mutation via Muller's rachet (Vorburger 2001, Howard \& Lively 2002). Nevertheless for the vast majority of organisms with the capacity to generate offspring both sexually and asexually, simple word models such as Williams' (1975) aphid-rotifer and 'strawberry-coral models' (SCM), and variants on this theme, still characterise our understanding of the proximate roles of sexual and asexual reproduction. In these models, organisms such as strawberries and corals typically use sexual reproduction to generate genotypically diverse colonists of distant or temporarily varying environments, while intense competition 
among colonists leads to selection for the fittest genotypes. The limited dispersal of asexually produced propagules is used to maintain populations comprised of locally adapted clones within relatively stable parental habitats.

There is strong empirical support for such apparently distinct roles of sexual and asexual reproduction in a range of terrestrial and freshwater systems, as judged by the relative dispersal of sexually and asexually produced propagules (e.g. Hebert et al. 1988, O'Connell \& Eckert 2001) and evidence for the localised adaptation of successful clones (Ayre 1985, 1995, Wilson \& Hebert 1992, Repka \& Walls 1998). Moreover, for clonal marine invertebrates, including sea anemones and corals, the general pattern of using asexual reproduction to maintain populations of locally adapted clones and sexual reproduction to produce widely dispersed colonists has seemed well supported (see Carvalho 1994). However, apparent exceptions to this pattern are found across a range of taxa, whereby successful clones are much more widely distributed than conspecific sexual lineages. In these cases clones may be 'generalist genotypes' or specialists that are well adapted to a widely distributed microhabitat (reviewed by Bell 1982 and by Hughes 1989; see also Wilson \& Hebert 1992, Chaplin \& Ayre 1997) including stressful areas at the extremes of the species range (Stearns 1987, Peck et al. 1998, Miller 1997)

In cases where genetic, histological and ecological approaches have been combined, the life-history of Pocillopora damicornis, one of the most studied and widespread corals, appears to fit some of the predictions of the $\mathrm{SCM}_{i}$ i.e. in Western Australia and Hawaii $P$. damicornis is hermaphroditic but can reproduce asexually via the production of brooded planulae and through fragmentation (Stoddart 1983, 1984a, 1988). Additionally, Stoddart \& Black (1985) and Ward (1992) have argued that in Western Australia the asynchronous developmental cycles of gametes and brooded planulae imply that colonies also reproduce sexually via broadcast-spawning. As predicted by the SCM, (1) local populations are numerically dominated by a small number of clones, (2) clones are typically restricted to single embayments or reef patches, and (3) the overall patterns of genotypic diversity, within the set of established clones, matches expectations for the widespread dispersal of sexually produced colonists (Stoddart 1984a,b, 1988).

Throughout the remainder of the geographic range of Pocillopora damicornis the available, and usually more fragmentary, evidence implies that its life-history is highly variable and that simple models such as the SCM may not always best describe the relative roles of sexual and asexual reproduction for population maintenance. Certainly throughout most of the Pacific, $P$. damicornis colonies are viviparous as well as simultaneous hermaphrodites (Harrison \& Wallace 1990, Glynn et al. 1991) and have branching growth forms (Veron 2000) that are thought to facilitate asexual reproduction and localised recruitment through fragmentation (Highsmith 1982, Richmond 1987-but see Smith \& Hughes 1999 for an experimental assessment of fragment survival). Within some areas, P. damicornis is claimed to exist as 2 distinct growth forms with asynchronous reproductive cycles (Richmond \& Jokiel 1984), and in the Eastern Pacific P. damicornis may not planulate but rather reproduce only via fragmentation (Richmond 1987) and broadcast-spawning (Glynn et al. 1991).

Interestingly, despite the range and extent of studies of Pocillopora damicornis, the role of gametes in the production of planulae remains equivocal. While it is clear that brooded planulae in Western Australia are generated asexually (Stoddart 1983), available evidence from other regions points to sexual production of planulae. For example, on Australia's Great Barrier Reef, where large numbers of brooded planulae are the conspicuous reproductive output of $P$. damicornis colonies (Harriott 1983, Harrison \& Wallace 1990, Tanner 1996), population genetic surveys by Benzie et al. (1995) and Ayre et al. (1997) of adult populations detected no evidence of localised asexual recruitment in reef-crest or reef-lagoon sites. Almost every colony displayed a distinct multi-locus allozyme genotype, and genotype frequencies either closely matched expectations for single and multi-locus Hardy-Weinberg equilibria (as expected for random mating) or were deficient in heterozygotes (as expected for inbred populations with limited dispersal of sexual progeny). Similarly, in Japan, population-genetic studies showed little evidence of asexual recruitment other than what could be attributed to fragmentation (Adjeroud \& Tsuchiya 1999), and a tight correlation between planulae development and the disappearance of sperm has been observed in histological studies (Diah Permata et al. 2000). Taken together, these data suggest sexual production of brooded planulae in these regions, in contrast to the asexual production that has been documented in Western Australia and Hawaii. Such variation in the mode of planulae production in a coral is unprecedented, and clearly genetic assessment of the similarity of adults and their broods, along with finescale analysis of the composition of populations, is needed to determine the mode of production of brooded larvae and the importance of asexual reproduction for recruitment.

Here we use genetic data to test the hypothesis that Pocillopora damicornis on the GBR utilises different reproductive tactics from those displayed by Western Australian and Hawaiian populations. We assess the 
importance of asexual reproduction and clonal recruitment by comparing the genotypes of adults and their brooded planula larvae and by examining the finescale patterns of genotypic diversity within samples of both adults and neighbouring sub-adult colonies.

\section{MATERIALS AND METHODS}

Collection of specimens. Larvae and settlers: To determine the mode of production of brooded planulae, we obtained newly released larvae from 11 adult colonies in October and November 2001, by maintaining adults in an open seawater system, on water tables, at the University of Sydney's One Tree Island Field Station, Great Barrier Reef (GBR) (Latitude 2330', Longitude $152^{\circ} 5^{\prime}$ ). We collected these colonies from a variety of reef-crest and reef-flat sites and maintained them under a gentle flow regime in separate aquaria. Each morning we collected larvae from plankton mesh-lined overflow 'traps' or siphoned them from the bottom of the aquaria. We then either used these live free-swimming larvae for electrophoresis (within $5 \mathrm{~d}$ of release) or in 4 cases, we allowed sets of larvae to settle and metamorphose. We maintained these 'settlers' for approximately $1 \mathrm{mo}$ in separate aquaria prior to electrophoresis at the One Tree Island Field Station.

Adults and juveniles: To test for evidence of localised asexual recruitment, we collected tissue samples (branch tips) from sets of 30 adults $(>15 \mathrm{~cm}$ maximum colony diameter) and 30 'juveniles' $(<7 \mathrm{~cm}$ maximum colony diameter) from 2 pairs of neighbouring (approx. $50 \mathrm{~m}$ separation) reef crest sites within each of 2 locations that were separated by $\sim 2 \mathrm{~km}$. We only classified colonies as juveniles if they displayed a symmetrical growth form consistent with growth from a settled larva rather than the regrowth of a portion of an older colony (i.e fragmentation). Sites were $36 \mathrm{~m}^{2}$ quadrats, this being the minimum area within which we could consistently collect sets of 30 adults and 30 juveniles. We froze these samples in liquid nitrogen and transported them to the University of Wollongong, where they were stored at $-80^{\circ} \mathrm{C}$ prior to electrophoresis.

Allozyme electrophoresis and data analysis. We carried out allozyme electrophoresis using $11 \% \mathrm{w} / \mathrm{v}$ starch gels (using equal weights of hydrolysed Sigma and Starch Art starch). Our tissue extractions, buffer conditions and staining procedures followed the methods described in Ayre et al. (1997) except that our assessment of the genotypes of brooding adults and their brooded larvae were achieved by staining at ambient temperature at the One Tree Island Field Station $\left(28\right.$ to $32^{\circ} \mathrm{C}$, compared to $37^{\circ} \mathrm{C}$ under normal laboratory conditions). Alleles are described by their mobil- ity relative to that of the most common allele at each locus and loci were numbered in order of decreasing electrophoretic mobility.

Assessment of genotypes adults and broods. We determined the genotypes of adults and their brooded larvae for 7 allozyme loci that had previously been found to be variable at sites within the GBR (Ayre et al.1997): glucose-phosphate isomerase (Gpi, E.C. 5.3.1.9), malate dehydrogenase $\left(M d h^{1+2}, \mathrm{EC} 1.1 .1 .37\right)$ and mannose phosphate isomerase (Mpi, E.C. 5.3.1.8) using Buffer No. 5 (TC8), and leucyl tyrosine peptidase $\left(L t p^{1+2}\right.$, E.C. 3.4.11) and leucyl proline peptidase ( $L p p$, E.C. 3.4.11) using Buffer No. 6 (TEB) of Selander et al. (1971). However only Gpi, Mpi and $L t p^{1+2}$ were both variable and consistently resolvable in our samples. As we were only able to assay each individual larva or settler on a single-buffer system, where possible we selected loci for which the broodparent was known to be heterozygous. To ensure that each locus represented an independent test of our hypotheses, we tested for linkage disequilibrium using Genepop v3.2a (Raymond \& Rousset 1995). We detected no evidence of significant linkage disequilibria ( $p>0.05$ ).

On average, the maximum proportion of a brood that could be identically heterozygous to the broodparent and yet be generated via sexual reproduction is 0.5 , the value expected for self-fertilisation or exclusive mating with either another identically heterozygous individual(s) or an individual homozygous for 1 of the 2 broodparent alleles. We therefore calculated the maximum probability that sets of ' $n$ ' brooded planulae or settlers could be identically heterozygous at 1 or more loci (as a result of sexual reproduction) as the product of the single-locus probabilities where for any given locus: $\mathrm{p}=0.5^{\mathrm{n}}$. This assumes independent assortment and free recombination (Black \& Johnson 1979).

Assessment of genotypic diversity within sites. We surveyed allozyme variation in adults and recruits for 7 variable loci. These loci included 4 described above, and phosphoglucomutase (Pgm, EC 2.7.5.1) and hexokinase $\left(\mathrm{Hk}^{1+2}\right.$, EC 2.7.1.1) as described by Ayre et al. (1997) and Miller \& Ayre (2004), respectively. We used several approaches to determine genotypic diversity and to infer the relative contributions of sexual and asexual reproduction to the genetic composition of samples from each site. First, we tested for departures from the levels of heterozygosity expected for singlelocus Hardy-Weinberg equilibria using the program Genepop v3.2a (Raymond \& Rousset 1995). We expressed these departures as $f$, where positive and negative values represent deficits or excesses or heterozygotes, respectively. Deficits are expected as a result of inbreeding or self-fertilisation whereas asexual reproduction should produce some cases of both heterozygous excesses and deficits (Willis \& Ayre 
1985). We assessed the statistical significance of departures by calculating exact probabilities, although we adjusted the probability values by applying a sequential Bonferroni correction. Second, we determined the 7-locus genotype of each colony and counted the number of unique genotypes per site $\left(N_{g}\right)$. Because we sampled only a tiny portion of the genome, colonies with identical multi-locus genotypes may still be non-clonemates. The ratio $N_{g}: N$ therefore represents a maximal estimate of the contribution of asexual reproduction to localised recruitment. Additionally we estimated the probability (p) that any genotype represented by $>2$ adults or juveniles within a given site could have been generated by sexual reproduction given the adult allele frequencies within the site (assuming random mating and free recombination). These probabilities were calculated as

$$
\mathrm{p}={ }^{n-1} C_{\mathrm{r}-1} \times p^{(r-1)} \times q^{(n-r)}
$$

where $C=$ the number of combinations, $n=$ the number of individual colonies, $\mathrm{p}=$ the probability of occurrence of a single copy of the 7 -locus genotype given random mating, $q=1-\mathrm{p}$ and $r=$ number of replicates of the genotype (Willis \& Ayre 1985). Finally we calculated the ratio of observed 7-locus genotypic diversity $\left(G_{0}\right)$ to that expected under conditions of random mating and free recombination $\left(G_{\mathrm{e}}\right)$ (Stoddart \& Taylor 1988). Departures of $G_{\mathrm{o}}: G_{\mathrm{e}}$ from unity should reflect the combined effects of departures from single-locus Hardy-Weinberg equilibria and multi-locus linkage disequilibria. Such departures are a predictable consequence of asexual reproduction (but may also result from other factors such as population subdivision; Ayre \& Hughes 2000).

Assessment of genetic variation among sites. We assessed levels of allelic differentiation among sites using F-statistics, calculated as Weir \& Cockerhams' $\theta$, using the software package TFPGA (Miller 2000). For these analyses, adult and juvenile colonies were pooled at each site. Mean values of $\theta( \pm$ SE) were calculated by jacknifing over loci. Departures from panmixis among sites (i.e. $\theta=0$ ) were tested using the $95 \%$ confidence intervals of $\theta$, calculated by bootstrapping over loci. To test the hypothesis that clones are dispersed among sites we also estimated the number and proportion of 7-locus genotypes shared among sites.

\section{RESULTS}

\section{Genetic tests of mode of larval production}

All newly released planula larvae and all 4 wk old settlers within each of 1 broods assayed displayed electrophoretic phenotypes identical to those of their brood parents for up to 7 allozyme loci $(n=350$ single locus assessments) (Table 1). These results cannot be explained by either outcrossed sexual reproduction or inbreeding (including self-fertilisation) but exactly match the outcome predicted for clonal replication; i.e. we detected only those alleles displayed by the broodparent within each of 11 broods despite the fact that colonies at One Tree Island display considerable polymorphism for most of the enzymes assayed, including 6 and 7 alleles at the Mpi and Gpi loci respectively (Table 2). Moreover, for 9 of the 11 broods, we detected $\geq 5$ larvae that each displayed the same heterozygous genotype as their broodparent, which is significantly unlikely to occur even as a result of self-fertilisation $(p=0.03)$. At the extreme, between 5 and 22 larvae of Colony 2 were identically heterozygous for each of 3 loci (combined probability of occurrence through sexual reproduction $\left.=2.91 \times 10^{-11}\right)$ (Table 1$)$.

Similarly, we found that in all 4 cases in which sets of larvae had been allowed to settle and metamorphose (settlers) their phenotypes were identical to those of their broodparents ( $\mathrm{n}=133$ single locus assessments), including 5 cases where sets of adults and their offspring were identically heterozygous at a given locus ( $\mathrm{n}=77$ single-locus assessments). Once again this level of genotypic replication can only be satisfactorily explained as consequence of asexual reproduction. For example, the probability of the observed level of replication of Gpi heterozygotes within the settlers of each of Colonies 2, 15 and 18 is $<4 \times 10^{-6}$ (Table 1).

\section{Fine-scale patterns of genotypic diversity}

The patterns of single- and multi-locus genotypic diversity detected within each of the 4 sites and within the groups of both adults and recruits were always consistent with sexually rather than asexually derived recruitment.

Within all 4 sites, the single-locus genotype frequencies of both adults and juveniles provided a relatively poor fit to values expected under Hardy-Weinberg equilibria, but were consistent with our expectations for sexually derived recruitment via self-fertilisation or inbreeding (Table 3). We found consistent heterozygote deficits for both adults and juveniles for 5 of the 7 loci (33 of 40 single-locus tests; Table 3). After Bonferroni adjustment of alpha values, departures from expected levels of heterozygosity were significant in only 5 instances, although these reflected large heterozygote deficiencies in all cases.

Generally, all collections contained approximately the levels of multi-locus genotypic diversity expected for random mating (Table 4). Overall we detected 148 distinct 7 -locus genotypes and diversity varied little 
among sites, with $N_{g}: N$ ranging from 0.64 within Site 1, to 0.87 in Site 4 (Table 4). Our complete collection of adult colonies displayed $90 \%$ of the 7 -locus genotypic diversity expected for outcrossed sexual reproduction $\left(G_{0}: G_{\mathrm{e}}=0.9\right)$, and values for individual sites ranged from 0.87 to 1.03 (Table 4). Generally, the values of $G_{0}: G_{\mathrm{e}}$ for juvenile colonies at each site were slightly lower than for adults, ranging from 0.72 to 0.93 ; however, in all cases $G_{\mathrm{o}}$ was judged not significantly different from $G_{\mathrm{e}}(\mathrm{p}>0.05)$.
We detected only 37 cases in which identical genotypes were shared by 2 or more colonies (maximum of 6 adults and recruits combined) within each of the 4 sites. However, using the allele frequencies detected within each site this level of replication was significantly unlikely for random mating in only 9 of the 37 cases $(p<0.05)$ and only 1 case remained significant after application of a Bonferroni correction; 4 cases remained significant after Bonferroni corrections if we used pooled allele frequencies for all 4 sites.
Table 1. Pocillopora damicornis. Allozyme genotypes (7-locus types) of parents and their brooded offspring (free-swimming larvae) or settled and metamorphosed juveniles (settlers) from One Tree Island, Great Barrier Reef, Australia. Loci $=$ Gpi: glucose-phosphate isomerase; Mpi: mannose phosphate isomerase; Mdh: malate dehydrogenase; Ltp: leucil tyrosine peptidase; Lpp: leucil proline peptidase

\begin{tabular}{|c|c|c|c|c|c|c|c|c|c|c|c|}
\hline \multirow[t]{2}{*}{ Locus } & \multicolumn{11}{|c|}{ Colony no. } \\
\hline & 2 & 11 & 14 & 15 & 18 & 30 & 33 & 39 & 41 & 43 & 44 \\
\hline \multicolumn{12}{|l|}{ Gpi } \\
\hline Parent & $\mathrm{BC}$ & $\mathrm{BC}$ & $\mathrm{AD}$ & $\mathrm{AD}$ & $\mathrm{AC}$ & $\mathrm{AC}^{\prime}$ & $C D$ & DD & DD & $\mathrm{AC}$ & $C^{\prime} D$ \\
\hline Larvae & $\begin{array}{l}\mathrm{BC} \\
(22)\end{array}$ & $\begin{array}{l}\mathrm{BC} \\
(6)\end{array}$ & & & $\begin{array}{c}\mathrm{AC} \\
(4)\end{array}$ & $\begin{array}{l}\mathrm{AC}^{\prime} \\
(15)\end{array}$ & $\begin{array}{l}\text { CD } \\
(7)\end{array}$ & $\begin{array}{l}\text { DD } \\
(10)\end{array}$ & $\begin{array}{l}\text { DD } \\
\text { (5) }\end{array}$ & $\begin{array}{c}\mathrm{AC} \\
(4)\end{array}$ & $\begin{array}{l}C^{\prime} D \\
(5)\end{array}$ \\
\hline Settlers & $\begin{array}{l}\text { BC } \\
(20)\end{array}$ & & $\underset{(4)}{\mathrm{AD}}$ & $\begin{array}{l}\mathrm{AD} \\
(18)\end{array}$ & $\mathrm{AC}$ & (27) & & & & & \\
\hline \multicolumn{12}{|l|}{ Mpi } \\
\hline Parent & $\mathrm{AB}$ & $\mathrm{BB}$ & $\mathrm{BB}$ & $\mathrm{BB}$ & $\mathrm{BB}$ & $\mathrm{AB}$ & $\mathrm{BB}$ & $\mathrm{AB}$ & $\mathrm{AB}$ & $\mathrm{BB}$ & $\mathrm{AA}$ \\
\hline Larvae & $\begin{array}{c}\mathrm{AB} \\
(5)\end{array}$ & & & & & $\begin{array}{l}\mathrm{AB} \\
(10)\end{array}$ & & $\begin{array}{l}\mathrm{AB} \\
(10)\end{array}$ & $\begin{array}{c}\mathrm{AB} \\
(5)\end{array}$ & $\begin{array}{l}\mathrm{BB} \\
\text { (4) }\end{array}$ & $\underset{(5)}{\mathrm{AA}}$ \\
\hline Settlers & & & & & $\begin{array}{l}\text { BB } \\
(6)\end{array}$ & & & & & & \\
\hline \multicolumn{12}{|l|}{$M d h^{1}$} \\
\hline Parent & AA & AA & $\mathrm{AA}$ & AA & $\mathrm{AA}$ & AA & $\mathrm{AA}$ & AA & $\mathrm{AA}$ & $\mathrm{AA}$ & $\mathrm{AA}$ \\
\hline Larvae & $\begin{array}{c}\text { AA } \\
(3)\end{array}$ & & & & & $\begin{array}{c}\text { AA } \\
(6)\end{array}$ & & & & & \\
\hline Settlers & $\begin{array}{c}\text { AA } \\
(8)\end{array}$ & & & $\begin{array}{l}\text { AA } \\
\text { (10) }\end{array}$ & $\begin{array}{l}\text { AA } \\
\text { (5) }\end{array}$ & & & & & & \\
\hline \multicolumn{12}{|l|}{$M d h^{2}$} \\
\hline Parent & AA & $\mathrm{AA}$ & $\mathrm{AA}$ & AA & $\mathrm{AA}$ & AA & $\mathrm{AA}$ & & & & \\
\hline Larvae & & & & & & $\begin{array}{c}\mathrm{AA} \\
(6)\end{array}$ & & & & & \\
\hline \multicolumn{12}{|l|}{ Settlers } \\
\hline \multicolumn{12}{|l|}{$L t p^{1}$} \\
\hline Parent & $\mathrm{AB}$ & $\mathrm{AA}$ & $\mathrm{AA}$ & AA & AA & AA & & $\mathrm{AA}$ & $\mathrm{AC}$ & AA & $\mathrm{AB}$ \\
\hline Larvae & $\begin{array}{c}\mathrm{AB} \\
(8)\end{array}$ & & & & & $\begin{array}{l}\text { AA } \\
(12)\end{array}$ & & $\begin{array}{l}\mathrm{AA} \\
(10)\end{array}$ & $\begin{array}{c}\mathrm{AC} \\
(5)\end{array}$ & $\begin{array}{l}\text { AA } \\
\text { (4) }\end{array}$ & $\begin{array}{l}\mathrm{AB} \\
(5)\end{array}$ \\
\hline Settlers & $\underset{(8)}{A B}$ & & & $\begin{array}{c}\text { AA } \\
(2)\end{array}$ & $\begin{array}{c}\text { AA } \\
(6)\end{array}$ & & & & & & \\
\hline \multicolumn{12}{|l|}{$L t p^{2}$} \\
\hline Parent & AA & AA & $\mathrm{AA}$ & AA & AA & $\mathrm{AA}$ & & $\mathrm{AA}$ & $\mathrm{AC}$ & AA & $\mathrm{AB}$ \\
\hline Larvae & $\begin{array}{c}\text { AA } \\
\text { (8) }\end{array}$ & & & & & $\begin{array}{l}\text { AA } \\
(12)\end{array}$ & & $\begin{array}{l}\mathrm{AA} \\
(10)\end{array}$ & $\begin{array}{c}\mathrm{AC} \\
(5)\end{array}$ & $\begin{array}{c}\text { AA } \\
(4)\end{array}$ & $\begin{array}{l}\mathrm{AB} \\
(5)\end{array}$ \\
\hline Settlers & $\begin{array}{c}\text { AA } \\
(8)\end{array}$ & & & $\begin{array}{c}\text { AA } \\
(2)\end{array}$ & $\begin{array}{c}\text { AA } \\
(6)\end{array}$ & & & & & & \\
\hline \multicolumn{12}{|l|}{$L p p$} \\
\hline Parent & AA & AA & $\mathrm{AA}$ & AA & AA & $\mathrm{AA}$ & & $\mathrm{AA}$ & $\mathrm{AA}$ & AA & $\mathrm{AA}$ \\
\hline Larvae & $\begin{array}{l}\text { AA } \\
\text { (5) }\end{array}$ & & & & & $\begin{array}{l}\text { AA } \\
(12)\end{array}$ & & $\begin{array}{l}\mathrm{AA} \\
(10)\end{array}$ & $\underset{(5)}{\mathrm{AA}}$ & $\begin{array}{c}\text { AA } \\
(4)\end{array}$ & $\underset{(5)}{\mathrm{AA}}$ \\
\hline Settlers & & & & $\begin{array}{l}\text { AA } \\
(2)\end{array}$ & $\begin{array}{l}\text { AA } \\
\text { (1) }\end{array}$ & & & & & & \\
\hline
\end{tabular}

\section{Genetic variation among sites}

Our collections of Pocillopora damicornis from all sites were genotypically diverse and showed little variation in numbers of alleles per site although we detected small but significant variation in allele frequencies (mean $F_{\mathrm{ST}}=0.044 \pm 0.025 \mathrm{SE}_{\mathrm{i}}$ $95 \%$ CI 0.004 - 0.078) among sites separated by as little as $50 \mathrm{~m}$. Levels of allelic diversity ranged from 6 and 7 alleles at the Mpi and Gpi loci respectively to 2 alleles at the $L t p^{2}$ locus (Table 2).

We found that 27 of the 1487 -locus genotypes occurred in 2 or more sites (3 sites in each of 3 cases). However, the maximum level of replication that we detected was a genotype shared by 10 colonies within Site 1, and the average level of replication for the 27 genotypes shared among sites was $3.6 \pm 0.2$. In 17 cases, replicated genotypes were shared among only 2 sites and were represented by a single individual at 1 or more of those sites.

\section{DISCUSSION}

Our analyses of the genotypic composition of the brooded offspring of Pocillopora damicornis from Australia's Great Barrier Reef strongly challenge both the idea that this widespread species exhibits geographic variation in its reproductive tactics (Harrison \& Wallace 1990, Knowlton \& Jackson 1994, Ayre et al. 1997) and also the predicted roles of sexual and asexual reproduction in the life-histories of organisms such as corals 
(Williams 1975, Hughes et al. 1992, Carvalho 1994). We found that the brooded planulae of $P$. damicornis from the highly heterogeneous reef-crest habitat of One Tree Island Reef on the southern GBR, like their counterparts from the physically stable and less species-rich reefs of Western Australia and Hawaii, are clonal replicates of their broodparents. Paradoxically, however, our data support previous claims that asexually derived recruitment has little or no apparent impact on the genetic composition of a range of GBR populations of P. damicornis (Benzie et al. 1995, Ayre et al. 1997). On theoretical grounds, this lack of localised asexual recruitment is unsurprising since the reefcrest habitat of the GBR supports one of the world's most speciose, diverse and dynamic macroinvertebrate communities. The reef crest may therefore be too heterogeneous to allow the restocking of discrete parental microhabitats by locally adapted clones, as envisaged in the majority of models that seek to explain the role of asexual reproduction (e.g. Williams 1975). From an

Table 2. Pocillopora damicornis. Allele frequencies for adult ( $>15 \mathrm{~cm}$ diameter) and juvenile colonies $(<7 \mathrm{~cm}$ diameter) collected from 4 sites on One Tree Reef, Great Barrier Reef. Pgm: phosphoglucomutase; Hk: hexokinase. Other abbreviations as in Table 1

\begin{tabular}{|c|c|c|c|c|c|c|c|c|}
\hline \multirow{2}{*}{$\begin{array}{l}\text { Locus/ } \\
\text { allele }\end{array}$} & \multicolumn{4}{|c|}{ Southern Reef Crest } & \multicolumn{4}{|c|}{ Northern Reef Crest } \\
\hline & Juvenile & Adult & Juvenile & Adult & Juvenile & Adult & Juvenile & Adult \\
\hline \multicolumn{9}{|l|}{ Gpi } \\
\hline A & 0.155 & 0.167 & 0.034 & 0.083 & 0.117 & 0.267 & 0.033 & 0.050 \\
\hline $\mathrm{B}$ & - & - & - & - & - & - & - & 0.017 \\
\hline $\mathrm{C}$ & 0.034 & - & 0.103 & 0.033 & 0.017 & - & 0.050 & 0.083 \\
\hline $\mathrm{D}$ & 0.310 & 0.400 & 0.241 & 0.217 & 0.400 & 0.367 & 0.233 & 0.217 \\
\hline $\mathrm{E}$ & 0.483 & 0.433 & 0.517 & 0.617 & 0.467 & 0.367 & 0.650 & 0.600 \\
\hline $\mathrm{F}$ & 0.017 & - & 0.017 & 0.017 & - & - & 0.017 & 0.033 \\
\hline G & - & - & 0.086 & 0.033 & - & - & 0.017 & - \\
\hline $\mathrm{n}$ & 29 & 30 & 29 & 30 & 30 & 30 & 30 & 30 \\
\hline \multicolumn{9}{|l|}{ Pgm } \\
\hline $\mathrm{A}$ & - & - & - & - & - & - & 0.017 & - \\
\hline B & 1 & 1 & 0.983 & 0.9 & 1 & 1 & 0.933 & 0.833 \\
\hline C & - & - & 0.017 & 0.1 & - & - & 0.050 & 0.167 \\
\hline $\mathrm{n}$ & 29 & 30 & 29 & 30 & 30 & 30 & 30 & 30 \\
\hline \multicolumn{9}{|l|}{ Mpi } \\
\hline A & - & 0.017 & 0.086 & 0.133 & - & - & 0.1 & 0.067 \\
\hline B & - & - & 0.017 & - & - & - & - & - \\
\hline $\mathrm{C}$ & 0.655 & 0.700 & 0.086 & 0.333 & 0.400 & 0.583 & 0.217 & 0.550 \\
\hline D & - & - & 0.552 & 0.317 & 0.200 & 0.067 & 0.200 & 0.083 \\
\hline $\mathrm{E}$ & 0.345 & 0.283 & 0.241 & 0.183 & 0.400 & 0.350 & 0.450 & 0.250 \\
\hline $\mathrm{F}$ & - & - & 0.017 & 0.033 & - & - & 0.033 & 0.050 \\
\hline $\mathrm{n}$ & 29 & 30 & 29 & 30 & 30 & 30 & 30 & 30 \\
\hline \multicolumn{9}{|l|}{$M d h^{2}$} \\
\hline A & 1 & 0.966 & 0.870 & 0.920 & 1 & 0.983 & 1 & 0.983 \\
\hline B & - & - & 0.109 & - & - & - & - & - \\
\hline $\mathrm{C}$ & - & 0.034 & 0.022 & 0.080 & - & 0.017 & - & 0.017 \\
\hline $\mathrm{n}$ & 29 & 29 & 23 & 25 & 30 & 30 & 28 & 29 \\
\hline \multicolumn{9}{|l|}{$L t p^{2}$} \\
\hline $\mathrm{A}$ & 0.879 & 0.833 & 0.793 & 0.950 & 0.767 & 0.783 & 0.617 & 0.683 \\
\hline B & 0.121 & 0.167 & 0.207 & 0.050 & 0.233 & 0.217 & 0.383 & 0.317 \\
\hline $\mathrm{n}$ & 29 & 30 & 29 & 30 & 30 & 30 & 30 & 30 \\
\hline \multicolumn{9}{|l|}{$H k^{1}$} \\
\hline A & 0.638 & 0.733 & 0.759 & 0.741 & 0.650 & 0.667 & 0.667 & 0.650 \\
\hline B & 0.362 & 0.250 & 0.241 & 0.241 & 0.350 & 0.333 & 0.333 & 0.350 \\
\hline $\mathrm{C}$ & - & 0.017 & - & 0.017 & - & - & - & - \\
\hline $\mathrm{n}$ & 29 & 30 & 29 & 29 & 30 & 30 & 30 & 30 \\
\hline \multicolumn{9}{|l|}{$H k^{2}$} \\
\hline A & 0.017 & - & - & - & - & - & - & - \\
\hline B & - & - & 0.017 & - & - & - & - & - \\
\hline $\mathrm{C}$ & 0.879 & 1 & 0.983 & 1 & 1 & 0.833 & 0.983 & 1 \\
\hline $\mathrm{D}$ & 0.103 & - & - & - & - & 0.167 & 0.017 & - \\
\hline $\mathrm{n}$ & 29 & 30 & 29 & 30 & 30 & 30 & 30 & 30 \\
\hline
\end{tabular}


evolutionary perspective, however, it is unclear how $P$. damicornis can maintain genotypically diverse populations that appear to be solely sexually derived and yet invest seemingly vast amounts of energy in a form of reproduction that is apparently not utilised. This is especially perplexing given that (1) the population structure of $P$. damicornis is quite similar to that of sympatric reef-crest populations of other brooding pocilloporid and acroporid corals, e.g. Stylophora pistillata, Seriatopora hystrix and Acropora cuneata (Resing \& Ayre 1985, Ayre \& Dufty 1994, Ayre \& Hughes 2000), some of which are known to brood sexually generated planulae (Ayre \& Resing 1986) and all of which also appear to have a similar potential for asexual reproduction through fragmentation as $P$. damicornis; and (2) in sharp contrast to the sometimes highly clonal reefcrest populations of the bushy but broadcast-spawning A. millepora and A. valida (Ayre \& Hughes 2000), which presumably undergo considerable fragmentation.

\section{Genetic evidence for asexual reproduction}

Historically there has been reluctance to accept the idea that broods of sexually mature cnidarians may be generated asexually (e.g. Ottaway \& Kirby 1975, Carter \& Thorpe 1979). However, our conclusion that this is occurring in Pocillopora damicornis is supported by the results of Stoddart's earlier work (Stoddart 1983,
Table 4. Pocillopora damicornis. Estimates of contribution of asexual reproduction in samples of 29 to 30 adults and juveniles from each of four $36 \mathrm{~m}^{2}$ reef crest sites on One Tree Island Reef, Great Barrier Reef, Australia. N: number of $G_{\mathrm{e}}$ : expected genotypic diversity $\left(G_{\mathrm{e}}\right.$ for juveniles was calculated on the basis of the allele frequencies for adult colonies at each site, but based on juvenile $N$ ). Significance levels of $G_{0}: G_{\mathrm{e}}$ from panmixis are following Bonferroni corrections for simultaneous tests. ns: not significant

\begin{tabular}{|lccccccc|}
\hline Population & $N$ & $N_{g}$ & $N_{g}: N$ & $G_{\mathrm{o}}$ & $G_{\mathrm{e}}( \pm \mathrm{SD})$ & $G_{\mathrm{o}}: G_{\mathrm{e}}$ & $\mathrm{p}$ \\
\hline $\begin{array}{l}\text { Site 1 } \\
\quad \text { Juveniles }\end{array}$ & 29 & 20 & 0.69 & 16.5 & $23.0(3.70)$ & 0.72 & $\mathrm{~ns}$ \\
$\quad$ Adults & 30 & 24 & 0.80 & 20.5 & $23.6(3.78)$ & 0.87 & $\mathrm{~ns}$ \\
$\quad$ Site 2 & & & & & & & \\
$\quad$ Juveniles & 30 & 23 & 0.77 & 17.3 & $22.8(3.86)$ & 0.76 & $\mathrm{~ns}$ \\
$\quad$ Adults & 30 & 26 & 0.87 & 23.7 & $22.8(3.86)$ & 1.03 & $\mathrm{~ns}$ \\
$\quad$ Site 3 & & & & & & & \\
$\quad$ Juveniles & 29 & 26 & 0.90 & 24.0 & $25.9(3.19)$ & 0.93 & $\mathrm{~ns}$ \\
$\quad$ Adults & 30 & 24 & 0.80 & 20.5 & $26.6(3.28)$ & 0.77 & $\mathrm{~ns}$ \\
$\quad \begin{array}{l}\text { Site 4 } \\
\quad \text { Juveniles }\end{array}$ & 30 & 26 & 0.87 & 22.5 & $27.2(3.12)$ & 0.83 & $\mathrm{~ns}$ \\
$\quad$ Adults & 30 & 27 & 0.90 & 25.0 & $27.2(3.12)$ & 0.92 & $\mathrm{~ns}$ \\
\hline
\end{tabular}

Stoddart \& Black 1985) with this species, and by the outcomes of other studies of reproduction both in sea anemones (e.g. Black \& Johnson 1979, Cutress 1979, Orr et al. 1982) and corals (Ayre \& Resing 1986). Furthermore, like these earlier studies, we utilised codominant markers, which are the most powerful means of interpreting mating systems, and have been used to provide the only unequivocal demonstrations of both sexual and asexual reproduction of coral broods, e.g. Acropora palifera (Ayre \& Resing 1986) and Ballanophylia elegans (Hellberg \& Taylor 2002) and the pocilloporid Seriatopora hystrix (Ayre \& Resing 1986).

Fixed heterozygosity within broods could result either from extreme selection favouring heterozygotes

Table 3. Pocillopora damicornis. Estimates of departures ( $f$ ) from levels of heterozygosity expected under conditions of HardyWeinberg equilibria at each of 7 allozyme loci, for samples of 29 to 30 adults and recruits from each of four $36 \mathrm{~m}^{2}$ reef crest sites on One Tree Island Reef, Great Barrier Reef, Australia. Positive values denote heterozygote deficits and negative values denote heterozygote excesses. Asterisks indicate values significantly different from expectations under Hardy-Weinberg equilibrium after Bonferroni correction $\left({ }^{*} \mathrm{p}<0.05 ;{ }^{* *} \mathrm{p}<0.01 ;{ }^{* * *} \mathrm{p}<0.001\right)$. Other abbreviations as in Table 1

\begin{tabular}{|c|c|c|c|c|c|c|c|c|}
\hline \multirow[t]{2}{*}{ Locus } & \multicolumn{4}{|c|}{ Southern Reef Crest } & \multicolumn{4}{|c|}{ Northern Reef Crest } \\
\hline & Juvenile & Adult & Juvenile & Adult & Juvenile & Adult & Juvenile & Adult \\
\hline Gpi & -0.159 & -0.189 & 0.003 & -0.247 & 0.069 & 0.245 & 0.188 & -0.014 \\
\hline Pgm & & & & & & 0.223 & -0.094 & 0.057 \\
\hline Mpi & 0.102 & $0.492^{*}$ & 0.393 & 0.203 & 0.240 & $0.442^{* *}$ & $0.470^{* * *}$ & 0.104 \\
\hline$M d h^{2}$ & & & -0.018 & & 0.638 & & 0.473 & \\
\hline$L t^{2}$ & 0.525 & $0.819^{*}$ & 0.532 & 0.714 & 0.385 & 0.519 & -0.036 & 0.474 \\
\hline$H k^{1}$ & 0.491 & 0.500 & 0.347 & $0.709^{*}$ & 0.263 & 0.414 & 0.049 & 0.065 \\
\hline$H k^{2}$ & 0.845 & & & 0.532 & & & & \\
\hline
\end{tabular}


or an artefact that causes apparently heterozygous phenotypes to be over-represented in these populations. However, we discount the possible effects of selection since we found identically heterozygous adults and broods for each of 4 apparently unlinked loci, including cases in which individual broods such as Colonies 2, 41 and 44 were heterozygous for 3 loci (Table 1). Moreover, our data and earlier studies of the structure of adult populations of Pocillopora damicornis on the southern GBR have revealed substantial heterozygous deficiencies within populations (Benzie et al. 1995, Ayre et al. 1997).

There has been evidence of delayed expression of the paternal genotype in allozyme phenotypes of broadcast-spawned coral larvae (i.e. Goniastrea favulus, Stoddart et al. 1988; Acropora spp., D. J. A. et al. unpubl.). However, this could not explain fixed heterozygosity within broods, since in these cases the expression of only the haploid maternal genotype caused larvae to initially appear to be single-banded homozygotes for each enzyme locus (i.e. not heterozygotes). Furthermore, in these studies, both maternal and paternal genotypes were consistently expressed at all loci between 5 and $18 \mathrm{~d}$ following fertilisation, and our larvae were all arguably too old for this to be a problem. We genotyped planulae that had already been brooded for at least several days (Diah Permata et al. 2000 suggest that the period from initiation of planula development to larval release in Pocillopora damicornis is likely to be about $2 \mathrm{wk}$ ) as well as metamorphosed settlers that were older than 1 mo of age and already forming growing colonies. Since all adult corals that we tested displayed phenotypes identical to those of their broods, including 198 brooded larvae that were heterozygous for at least 1 locus, we conclude that asexual reproduction was the source of each of the broods we examined.

\section{Genotypic structure of populations}

In contrast to the apparent importance of asexual reproduction in the generation of brooded larvae, the genotypic structure of groups of adult and juvenile colonies from all 4 sites revealed no evidence of clonality. Indeed we detected between 72 and $100 \%$ of the diversity that would be expected for randomly mating populations, using either the underlying gene frequencies detected within each site or across all 4 sites on the reef, and found that most individuals were genotypically unique. This is a very similar level of diversity to that reported from a wide range of sites for Pocillopora damicornis (Benzie et al. 1995, Ayre et al. 1997) and other brooding corals (Ayre \& Dufty 1994, Ayre \& Hughes 2000) including species with sexually gener- ated broods (Ayre \& Resing 1986). Moreover, the level of genotypic diversity is similar to that reported for South African populations of the broadcast-spawning P. verrucosa (Ridgway et al. 2001) and much greater than that of broadcast-spawning but apparently fragmenting species on the GBR (Ayre \& Willis 1988, Ayre $\&$ Hughes 2000). Some reduction in genotypic diversity below that expected for random mating is expected in $P$. damicornis, given the inevitably limited sperm dispersal (Oliver \& Babcock 1992, Levitan \& Petersen 1995) and potentially limited dispersal of brooded larvae (Harrigan 1972, Harrison \& Wallace 1990). Indeed all populations showed heterozygous deficiencies and statistically significant population subdivision that should depress observed levels of genotypic diversity (Stoddart \& Taylor 1988).

The striking contrast between our conclusions and both theoretical predictions and the outcomes of other studies appears to defy a simple evolutionary explanation. There are, however, at least 3 classes of hypotheses that might provide a proximate explanation for the existence of genotypically diverse population structure reported here and earlier (Benzie et al. 1995, Ayre et al. 1997), although each fails to provide an ultimate explanation for the evolution and persistence of this complex life-history, and appears poorly supported by our data and other aspects of the biology of this species.

First, genotypic diversity could be maintained at a local scale if brooded, clonal larvae are widely dispersed; i.e. larvae either originate in other habitats so that the reef crest is in effect a reproductive sink, or originate within other reef-crest sites. In either case this could provide diverse pools of recruits at each site and so might explain the lack of obvious clonality in reef-crest populations. These explanations are unsatisfactory on theoretical grounds as they require that an hermaphroditic organism with the capacity for sexual reproduction (Stoddart \& Black 1985, Ward 1992) should instead use asexual reproduction to colonise distant habitats but not its parental habitat patch, and we saw little apparent sharing of genotypes among reef-crest sites. Widespread dispersal of clonal propagules is usually seen only in cases where, in contrast to our data, populations are dominated by a few generalist genotypes (Wilson \& Hebert 1992, Mertens 1993, Chaplin \& Ayre 1997). Moreover, larval Pocillopora damicornis are competent to settle on emergence (Atoda 1947, Harrigan 1972) and did so from 24 to $72 \mathrm{~h}$ following release, when we harvested clonally generated larvae (K. J. M. \& D. J. A. pers. obs.).

Second, if asexually generated larvae from the reef crest are the principal form of recruits and they settle close to their broodparents, then diversity might be maintained by post-settlement processes of competition and selection. This would require that 148 differ- 
ent genotypes made an almost equal contribution to recruitment within each of our $36 \mathrm{~m}^{2}$ study sites. However, it seems unlikely that even on the physically and biologically heterogeneous reef crests these processes alone could maintain such uniformly high levels of diversity across a wide range of sites and regions (Benzie et al. 1995, Ayre et al. 1997) and, most importantly, we detected similarly high levels of genotypic diversity in both adults and recruits. In the long term it would seem unlikely that selection would favour the continued production of clonal broods in this species if clonal proliferation does not occur, and even if clones are initially founded by sexual colonists, interclonal competition would be expected to rapidly reduce levels of clonal diversity within sites (Spitze 1991).

Third, it is possible that our reef crest populations were formed and are maintained principally by sexually derived recruits (either brooded or broadcast spawned) arising either within the reef crest or from other habitats. Sexually derived recruitment could explain the large and consistent heterozygous deficiencies present within the reef-crest sites via either spatial or temporal Wahlund effects (e.g. Ayre \& Dufty 1994) or mating systems that involve self-fertilisation or inbreeding. Histological studies have been used to infer that individual Pocillopora damicornis may produce both clonal broods and undergo broadcast-spawning (Stoddart \& Black 1985, Ward 1992) (although the latter has not been observed) or that $P$. damicornis may brood sexually produced larvae (Diah Permata et al. 2000). However, if most recruits are derived from sexual reproduction this fails to explain both the persistence of asexual reproduction in the reef-crest populations and the fate of the huge numbers of clonal larvae generated within each site (Tanner [1996] recorded the release of over 2000 planulae from a single colony fragment over a $9 \mathrm{~d}$ period during a single lunar cycle).

The population structures we observed might be more readily explained if reef crests are atypical and Pocillopora damicornis in other habitats broods sexually generated larvae or, alternatively, if sexual and asexual recruitment vary in importance across years or decades. Certainly, most genetic studies of $P$. damicornis on the GBR (including the present study) have focused on reef-crest or shallow-water locations, which may bias our understanding of population structure and maintenance across a variety of reef habitats and regions. Temporal variation in the importance of recruitment, perhaps driven by cycles of disturbance and subsequent availability of suitable habitat, provides the most appealing explanation since it could be viewed as an extension of the intermediate disturbance hypothesis (Connell 1978). However, the patterns that we observed would require a response to disturbance that is the opposite of normal predictions for the roles of sexual and asexual reproduction in complex life-cycles.

Under the 'strawberry coral model', and indeed as has been observed for a range of cyclical parthenogens (see Carvalho 1994 for review), sexual reproduction is typically used to generate high levels of diversity around the time of major disturbance, e.g. freezing or drying of freshwater ponds producing a range of clones that compete to exploit the new and relatively stable habitat in the following season (Hebert 1974). This competition in turn leads to dramatic reduction in clonal diversity during the periods of relative stability, and high clonal population structures (Spitze 1991). Here however we are seeing both a major investment in asexual reproduction and high levels of genotypic diversity during a period of apparent habitat stability. The reefs of the Capricorn Bunker group (which includes One Tree and nearby Heron Islands) have been the subject of long-term ecological studies (Connell et al. 1997) and there are no accounts of widespread and severe disturbance of reef crest communities within the past 2 decades. Importantly, our data suggest there is no obvious temporal pattern of alternating sexual and asexual recruitment, since levels of genotypic diversity were very similar for adult and juvenile colonies. The age of coral colonies is notoriously difficult to estimate (Hughes \& Jackson 1980) but these 2 groups might easily differ in age by $10 \mathrm{yr}$. Moreover, the population structures that we observed are very similar to those detected by Benzie et al. (1995) and Ayre et al. (1997) in collections from the same region made in 1993 and 1992/93 respectively.

Resolution of this apparent paradox may require an extension of our sampling programme to determine modes of reproduction and recruitment in other habitats, on other reefs and at different times, in order to determine the source and diversity of recruits following disturbance, to test for evidence of more widespread dispersal of clones and to track the diversity of populations and the performance of individual genotypes over time. Ideally, such a study would compare reproductive output and recruitment processes on both the GBR and in Western Australia. In the meantime, the life-history of Pocillopora damicornis, the most intensively and extensively studied brooding coral, appears to be a very poor fit to classical predictions of the role of sexual and asexual reproduction on the Great Barrier Reef.

Acknowledgements. This work was supported by an ARC postdoctoral fellowship to K.J.M., an ARC discovery grant to D.J.A. and K.J.M., and by the University of Wollongong's Institute for Conservation Biology. We thank C. Mundy and C. Howard for excellent field and laboratory assistance. This work was conducted at the University of Sydney's One Tree Island research station, and we gratefully acknowledge the assistance of K. and P. Beinssen. M. S. Johnson provided useful discussions. 


\section{LITERATURE CITED}

Adjeroud M, Tsuchiya M (1999) Genetic variation and clonal structure in the scleractinian coral Pocillopora damicornis in the Ryukyu Archipelago, southern Japan. Mar Biol 134: $753-760$

Atoda K (1947) The larva and postlarval development of some reef-building corals. I. Pocillopra damicornis cespitosa (Dana). Sci Rep Tohoku Univ Fourth Ser (Biol)18:24-47

Ayre DJ (1985) Localized adaptation of clones of the sea anemone Actinia tenebrosa. Evolution 39:1250-1260

Ayre DJ (1995) Localised adaptation of sea anemone clones: evidence from transplantation over two spatial scales. J Anim Ecol 64:186-196

Ayre DJ, Dufty S (1994) Evidence for restricted gene flow in the viviparous coral Seriatopora hystrix on Australia's Great Barrier Reef. Evolution 48:1183-1201

Ayre DJ, Hughes TP (2000) Genotypic diversity and gene flow in brooding and spawning corals along the Great Barrier Reef, Australia. Evolution 54:1590-1605

Ayre DJ, Resing JM (1986) Sexual and asexual production of planulae in reef corals. Mar Biol 90:187-190

Ayre DJ, Willis BL (1988) Population structure in the coral Pavona cactus: clonalgenotypes show little phenotypic plasticity. Mar Biol 99:495-505

Ayre DJ, Hughes TP, Standish RJ (1997) Genetic differentiation, reproductive mode, and gene flow in the brooding coral Pocillopora damicornis along the Great Barrier Reef, Australia. Mar Ecol Prog Ser 159:175-187

Bell G (1982) The masterpiece of nature: the evolution and genetics of sexuality. Croom Helm, London

Benzie JAH, Haskell A, Lehman H (1995) Variation in the genetic composition of coral (Pocillopora damicornis and Acropora palifera) populations from different reef habitats. Mar Biol 121:731-739

Bernstein H, Hopf FA, Michod RE (1988) Is meiotic recombination an adaptation for repairing DNA, producing genetic variation or both? In: Michod RE, Levin BR (eds) The evolution of sex. Sinauer, Sunderland, MA, p 139-160

Black R, Johnson MS (1979) Asexual viviparity and population genetics of Actinia tenebrosa. Mar Biol 53:27-31

Carter MA, Thorpe CH (1979) The reproduction of Actinia equina L. var. mesembryanthemum. J Mar Biol Assoc UK 59:989-1001

Carvalho GR (1994) Evolutionary genetics of aquatic clonal invertebrates: concepts, problems and prospects. In: Beaumont AR (ed) Genetics and evolution of aquatic organisms. Chapman \& Hall, London, p 292-322

Chaplin JA, Ayre DJ (1997) Genetic evidence of widespread dispersal in an obligately parthenogenetic freshwater ostracod. Heredity 78:57-67

Connell JH (1979) Diversity in tropical rainforests and coral reefs - high diversity is maintained only in a non equilibrium state. Science 199:1302-1310

Connell JH, Hughes TP, Wallace CC (1997) A 30-year study of coral abundance, recruitment, and disturbance at several scales in space and time. Ecol Monogr 67:461-488

Cutress CE (1979) Bunodeopsis medusoides Fowler and Actinodiscus neglectu Fowler, two Tahitian sea anemones: redescription and biological notes. Bull Mar Sci 29:96-109

Diah Permata W, Kinzie RA III, Hidaka M (2000) Histological studies on the origin of planulae of the coral Pocillopora damicornis. Mar Ecol Prog Ser 200:191-200

Galvani AP, Coleman RM, Ferguson NM (2003) The maintenance of sex in parasites. Proc R Soc Lond B 270:19-28

Glynn PW, Gassman NJ, Eakin CM, Cortes J, Smith DB, Guzman HH (1991) Reef coral reproduction in the eastern
Pacific: Costa Rica, Panama and the Galapagos Islands (Ecuador). I. Pocilloporidae. Mar Biol 109:355-368

Harrigan JF (1972) Behavior of planula larva of the scleractinian coral Pocillopora damicornis (L). Am Zool 12:723

Harriott VJ (1983) Reproductive seasonality, settlement, and post-settlement mortality of Pocillopora damicornis (Linnaeus), at Lizard Island, Great Barrier Reef. Coral Reefs 2: 151-157

Harrison PL, Wallace CC (1990) Reproduction, dispersal and recruitment of scleractinian corals. In: Dubinsky Z (ed) Coral Reefs. Ecosystems of the world, Vol 25. Elsevier, Amsterdam, p 133-196

Hebert PDN (1974) Enzyme variability in natural populations of Daphnia magna. III. Genotype frequencies in intermittent populations. Genetics 77:335-344

Hebert PDN, Ward RD, Weider LJ (1988) Clonal-diversity patterns and breeding-system variation in Daphnia pulex, and asexual-sexual complex. Evolution 42:147-159

Hellberg ME, Taylor MS (2002) Genetic analysis of sexual reproduction in the dendrophylliid coral Balanophyllia elegans. Mar Biol 141:629-637

Highsmith RC (1982) Reproduction by fragmentation in corals. Mar Ecol Prog Ser 7:207-226

Howard RS, Lively CM (2002) The ratchet and the red queen: the maintenance of sex in parasites. J Evol Biol 15: 648-656

Hughes, RN (1989) A functional biology of clonal animals. Chapman \& Hall, London

Hughes TP, Jackson JBC (1980) Do corals lie about their age? Some demographic consequences of partial mortality, fission and fusion. Science 209:713-715

Hughes TP, Ayre DJ, Connell JH (1992) The evolutionary ecology of tropical corals. Trends Ecol Evol 7:292-295

Knowlton N, Jackson JBC (1994) New taxonomy and niche partitioning on corals reefs: jack of all trades or master of some? Trends Ecol Evol 9:7-9

Levitan DR, Petersen C (1995) Sperm limitation in the sea. Trends Ecol Evol 10:228-231

Lively CM (1992) Parthenogenesis in a fresh-water snailreproductive assurance versus parasitic release. Evolution 46:907-913

Mertens KL (1993) Origins of genotypic variation in North American dandelions inferred from ribosomal DNA and chloroplast DNA restriction enzyme analysis. Evolution 47:136-151

Miller KJ (1997) Genetic structure of black coral populations in New Zealand's fiords. Mar Ecol Prog Ser 161:123-132

Miller KJ, Ayre DJ (2004) The role of sexual and asexual reproduction in structuring high latitude populations of the reef coral Pocillopora damicornis. Heredity 92: $557-568$

O'Connell LM, Eckert CG (2001) Differentiation in reproductive strategy between sexual and asexual populations of Antennaria partinii (Asteracae). Evol Ecol Res 3:311-330

Oliver J, Babcock R (1992) Aspects of the fertilisation ecology of broadcast-spawning corals: Sperm dilution effects and in situ measurements of fertilisation. Biol Bull (Woods Hole) 183:409-417

Orr J, JP Thorpe, Carter MA (1982) Biochemical genetic confirmation of the asexual reproduction of brooded offspring in the sea anemone Actinia equina. Mar Ecol Prog Ser 7: $227-229$

Ottaway JR, Kirby GC (1975) Genetic relationships between brooding and brooded Actinia tenebrosa. Nature 255: 221-223

Peck JR, JM Yearsley, Waxman D (1998) Explaining the geographic nature of parthenogenesis. Nature 391:889-892 
Raymond M, Rousset F (1995) GENEPOP (Version 1.2): population genetics software for exact tests and ecumenicism. J Hered 86:248-249

Repka SM, Walls M (1998) Variation in the neonate size of Daphnia pulex: the effects of predator exposure and clonal origin. Aquat Ecol 32:203-209

Resing JM, Ayre DJ (1985) The usefulness of the tissue grafting bioassay as an indicator of clonal identity in scleractinian corals (Great Barrier Reef-Australia). Proc 5th Int Coral Reef Congr 6:75-81

Richmond RH (1987) Energetic relationships and biogeographical differences among fecundity, growth and reproduction in the reef coral Pocillopora damicornis. Bull Mar Sci 41:594-604

Richmond R(H), Jokiel PL (1984) Lunar periodicity in larval release in the reef coral Pocillopora damicornis at Enewatak and Hawaii. Bull Mar Sci 34:280-287

Ridgway T, Hoeugh-Gouldberg O, Ayre DJ (2001) Panmixia in Pocillopora verrucosa from South Africa. Mar Biol 139: 175-181

Seger J, Hamilton WD (1988) Parasites and sex. In: Micheod RE, Levin BR (eds) The evolution of sex. Sinauer, Sunderland, MA, p 176-193

Selander RK, Smith MH, Yang YS, Johnson WB, Gentry JB (1971) Biochemical polymorphism and systematics in the genus Peromyscus. I. Variation in the old-field mouse (Peromyscus polionotus). Stud Genet Soc Austin TX 6:49-90

Smith LD, Hughes TP (1999) An experimental assessment of survival, reattchment and fecundity of coral fragments. J Exp Mar Biol Ecol.235:147-165

Spitze K (1991) Chaoborus predation and life-history evolution in Daphnia pulex: temporal pattern of population diversity, fitness and mean life history. Evolution 45:82-92

Stearns S (ed) (1987) The evolution of sex and its consequences. Berhauser Verlag, Boston

Editorial responsibility: Roger Hughes (Contributing Editor), Bangor, UK
Stoddart JA (1983) Asexual production of planulae in the coral Pocillopora damicornis. Mar Biol 76:279-284

Stoddart JA (1984a) Genetic structure within populations of the coral Pocillopora damicornis. Mar Biol 81:19-30

Stoddart JA (1984b) Genetic differentiation amongst populations of the coral Pocillopora damicornis off southwestern Australia. Coral Reefs 3:149-156

Stoddart JA (1988) Coral populations fringing islands larval connections. Aust J Mar Freshw Res 39:109-116

Stoddart JA, Black R (1985) Cycles of gametogenesis and planulation in the coral Pocillopora damicornis. Mar Ecol Prog Ser 23:153-164

Stoddart JA, Taylor JF (1988) Genotypic diversity-estimation and prediction in samples. Genetics 118:705-711

Stoddart JA, Babcock RC, Heyward AJ (1988) Self-fertlization and maternal enzymes in the planulae of the coral Goniastrea favulus. Mar Biol 99:489-494

Tanner JE (1996) Seasonality and lunar periodicity in the reproduction of pocilloporid corals. Coral Reefs 15:59-66

Veron JEN (2000) Corals of the world. Australian Institute of Marine Science, Queensland

Vorburger C (2001) Fixation of deleterious mutations in clonal lineages: evidence from hybridogenetic frogs. Evolution 55:2319-2332

Ward S (1992) Evidence for broadcast spawning as well as brooding in the scleractinian coral Pocillopora damicornis. Mar Biol 112:641-646

Williams GC (1975) Sex and evolution. Princeton University Press, Princeton, NJ

Willis BL, Ayre DJ (1985) Asexual reproduction and genetic determination of growth form in the coral Pavona cactus: biochemical genetic and immunogenic evidence. Oecologia 65:516-525

Wilson CC, Hebert PDN (1992) The maintenance of taxon diversity in an experimental assemblage: an experimental analysis. Ecology 73:1462-1472

Submitted: September 15, 2003; Accepted: April 21, 2004 Proofs received from author(s): July 26, 2004 